\title{
Apuntes sociológicos de las inmigrantes suramericanas (Ecuador, Bolivia y Colombia) en Mallorca
}

\author{
Bartomeu Mulet Trobat \\ Catalina Oliver Cardell \\ Liliana Lorenzana Alvarez \\ Biel Gelabert Noguera \\ Francisco González Paredes \\ Universitat Illes Balears \\ Rosa Caramés Balo \\ Universidade da Coruña
}

\section{Resumen}

Se trata de visibilizar y mostrar las desigualdades de género en el marco de la diversidad cultural, en un contexto de multiculturalidad transcultural jerarquizada en Mallorca como sociedad receptora. Para constatar estos planteamientos se realizaron entrevistas en profundidad a mujeres afro-ecuatorianas y originarias, emigradas de Suramérica hacia Mallorca, registrando sus respuestas en un cuestionario-guía preestablecido. Éste fue contestado por 39 mujeres de origen étnico afroecuatoriano y originarias de Ecuador, Colombia y Bolivia. Estas mujeres constituyen una muestra y un ejemplo significativo de la feminización de la migración y la supervivencia colectiva.

Palabras clave

Inmigración; multiculturalidad; desigualdad; Suramérica; Mallorca

Códigos JEL: D63, J61, J7
SOCIOLOGICAL NOTES OF THE SOUTH AMERICAN FEMALE IMMIGRANTS (ECUADOR, BOLIVIA AND COLOMBIA) IN MALLORCA

\section{Abstract}

The aim is to make visible and show gender inequalities within the framework of cultural diversity, in a context of hierarchical cross-cultural multiculturalism in Mallorca as a host society. In order to verify these approaches, in-depth interviews were conducted with Afro-Ecuadorian women and indigenous natives, emigrated from South America to Mallorca, recording their responses in a pre-established questionnaire-guide. This was answered by 39 women of Afro-Ecuadorian and indigenous ethnicity from Ecuador, Colombia and Bolivia. They represent a significant aspect of the feminization of migration and collective survival.

Keywords

Immigration; multiculturalism; inequality; South America; Mallorca

JEL codes: D63, J61, J7

Fecha de recepción del original: 28 de noviembre de 2019; versión definitiva: 24 de julio de 2020.

Bartomeu Mulet Trobat (ORCID ID: 0000-0002-0182-295X), Catalina Oliver Cardell, Liliana Lorenzana Alvarez, Biel Gelabert Noguera y Francisco González Paredes. Universitat Illes Balears/Facultad de Educación, Edificio Guillem Cifre, Ctra de Valldemossa, km 7.5. Palma (Illes Balears) 07122.

E-mail: tom200@hotmail.es/tomeu.mulet@uib.es

Rosa Caramés Balo, Universidade da Coruña. 


\title{
Apuntes sociológicos de las inmigrantes suramericanas (Ecuador, Bolivia y Colombia) en Mallorca
}

\author{
Bartomeu Mulet Trobat \\ Catalina Oliver Cardell \\ Liliana Lorenzana Alvarez \\ Biel Gelabert Noguera \\ Francisco González Paredes \\ Universitat Illes Balears \\ Rosa Caramés Balo \\ Universidade da Coruña
}

Introducción

Dada la dimensión que han adquirido en Mallorca los fenómenos de la multiculturalidad y grupos étnicos, y dada la discriminación sociocultural de clase, género y etnia que se vive en las sociedades complejas, nos hemos propuesto, desde la óptica de la Sociología, y con una perspectiva multidisciplinar, analizar las características de la interrelación asimétrica de desigualdad que viven el género y la etnia (mujeres negras o afroamericanas (Ecuador) y originarias (Colombia y Bolivia).

La sociedad de la globalización a escala planetaria ha generado una sociedad multicultural jerarquizada transnacional y transcultural, en el sentido del pluralismo cultural y las relaciones interétnicas que indica G. Sartori $(2001)^{1}$, propiciando que el multiculturalismo vigente facilite la formación de guetos, discriminando y desintegrando a las minorías lo que implica desvirtuar e imposibilitar el desarrollo de un planteamiento realista de interculturalidad globalizada en el marco de la diversidad cultural, sin olvidar la tendencia homogeneizadora de la mundialización cultural etnocentrica (Macionis y Plummer, 2007: 121-132). El fenómeno de la multiculturalidad ${ }^{2}$ que aquí tratamos se refiere, básicamente, a las minorías que aterrizan en una sociedad concreta provenientes de los movimientos migratorios, fruto de la globalización moderna y en las sociedades complejas. En estos contextos multiculturales se producen desigualdades socioculturales, tensiones y conflictos, a menudo, silenciados cuando no ignorados o mediatizados por los medios de comunicación de masas (González Pérez y Somoza, 2004; Vecina, 2010: 5; Serra, 2006).

\footnotetext{
${ }^{1}$ El fenómeno transnacional y transcultural de que hablamos se refiere a la transculturación que aquí se entiende como una aculturación transnacional globalizante que afecta mayoritariamente a las culturas minoritarias o minorías culturales, lo que dificulta el respeto e impulso a la diversidad cultural, según el mismo G. Sartori, 2001.

2 Pretendemos explicar que mientras que multicultural hace referencia a la coexistencia en un mismo ámbito (generalmente territorial) de pueblos y culturas diferentes, intercultural se refiere a las actuaciones destinadas a conseguir que esa coexistencia se convierta en una convivencia fructífera y enriquecedora basada en un intercambio. Por lo tanto, lo intercultural es la consecuencia más deseable de lo multicultural.
}

Las exigencias de la sociedad actual de desigualdad, multiculturalidad y discriminación étnica urgen nuevas políticas culturales y educativas, para afrontar los nuevos retos. De no ser así, se producirá una involución y la brecha económica, cultural, social y educativa se ensanchará (Carbonell, 1995). Aquí resultan importantes las propuestas que se hagan de reorientación de los planteamientos multiculturales en el sistema escolar y de socialización (Carbonell, 2003: 155-176).

Tanto es así que las sociedades de la «tercera revolución industrial» no solo han visto aumentaren su senolas desigualdades sociales, sino crecer nuevas formas de desigualdad y de exclusión social, relacionadas con el aumento de la diversidad cultural de sus miembros, debido principalmente a las migraciones internacionales.

Efectivamente, los profundos cambios tecnológicos que hemos vivido principalmente en las tres últimas décadas están facilitando y estimulando los desplazamientos de una a otra parte del mundo. No solo de las mercancías y de los recursos, sino también de las ideas, de las imágenes, de los mensajes, etc., y de las personas, a veces casi alienadas por el deseo de vivir en aquellos paraísos del consumo compulsivo que ofrecen las seductoras imágenes de la publicidad y los medios de comunicación masivos que hoy se difunden por todo el planeta.

Stuart Hall, uno de los padres de los Estudios Culturales Británicos, reconocido sociólogo y teórico "culturalista", pionero del análisis del multiculturalismo, dice que la trilogía raza, etnia y nación, “... significa repensar la diferencia cultural en términos discursivos, discurso ha de entenderse como aquello que otorga significado a la práctica humana y a las instituciones, aquello que nos permite dar sentido al mundo, y, por consiguiente, aquello que hace que las prácticas humanas sean prácticas significativas y formen parte de la historia, precisamente porque gozan de significado en tanto señalan las diferencias humanas. Planteaba recomponer estos conceptos asignados tradicionalmente a explicar la diferencia cultural, raza, etnia, nación, "a un análisis discursivo-genealógico, a tenor de ciertas preocupaciones políticas y teóricas; quiero también usar cada término para complejizar y desestabilizar un poco los otros dos" (Hall, 2019: 45). Desigualdad étnica y líneas de poder eran temas preferidos por Hall. Se trata de todo un complejo de relaciones de poder que facilitan la jerarquización de las capas de población más 
vulnerables, reverberando guetización, racismo, xenofobia, precariedad laboral y exclusión social (Van Dijk, 2003).

Respecto a la diversidad cultural, también se encuentran presentes conceptos y variables diversos como clase social, exclusión social, racismo, xenofobia, explotación socioeconómica, precariedad y discriminación étnica, cuestiones que se interrelacionan en una sociedad contradictoria. Por un lado, la sociedad demanda solidaridad y diversidad cultural, y por otro, impulsa la discriminación etnocéntrica. (Mayoral y Mateo, 2012: 234-235) Esta discriminación provoca reacciones violentas en las capas de población más marginales de la sociedad, entre ellas las inmigradas, todo ello en un contexto de alta competitividad capitalista y de explotación, lo que genera nuevas formas de exclusión social que condicionan el desarrollo de una diversidad cultural digna para todos (Delgado y otros, 2002).

La diversidad cultural debe suponer la superación de las culturas cerradas en sí mismas y la «guetización» con un grado de asimilación significativo (Macionis, 2007: 284; Garreta, 2009: 1317). La normalización cultural de una comunidad, de un pueblo, de una colectividad, no implica solo a la lengua sino a toda una dinámica cultural que facilite no solo rutinas, favoreciendo pautas de interacción social no folclorizadas. En este sentido, hay que tener presente las diferentes concepciones de diversidad cultural, multiculturalidad e interculturalidad dado que ya existen varias propuestas de estudio en este sentido, desde autores como Clifford Geeztz (1996), James Clifford (1995), Humbert Hannoun (1987), Giovanni Sartori (2001), Will Kymlicka (1996), C. Labat, y G. Vermes (1994), Hans M. Enzensberger (2001), Laura Zanfrini (2007), Stuart Hall (2019) en el ámbito internacional. Estos conceptos precisan ser clarificados (cultura, diversidad cultural, multiculturalidad e interculturalidad) en las Ciencias Sociales.

En este marco teórico queda bastante claro que no todos los conceptos que hacen referencia a la multiculturalidad tienen los significados que parece debido a que el uso que se hace depende de los contextos, y no es unívoco. Es decir, el concepto de interculturalidad, es utilizado de manera diferente según las regiones y los autores. Multiculturalidad parece que debería significar variedad de culturas en un contexto sin demasiado contacto, e interculturalidad contacto dinámico y enriquecedor (Busquet, 2005: 82). Aunque, teóricamente, la interculturalidad sea el concepto más cercano a la diversidad cultural, en la práctica la multiculturalidad en que se manifiesta es muy discutible y muestra poco respeto. No se consigue el objetivo teórico de multiculturalidad diversa que podría asociarse a la interculturalidad. La multiculturalidad es un paso para modernizar el asimilacionismo tradicional.

El concepto de diversidad cultural se puede relacionar con los significados de identidad cultural, interculturalidad y multiculturalidad, que implican el contacto entre varias lenguas, etnias, religiones, expresiones artísticas, valores, gastronomías y cosmovisiones (UNESCO, 2001 y Macionis, 2007: 107-118). Aquí consideramos la diversidad cultural en su relación con la globalización y la mundialización con sus contradicciones y paradojas provocadoras de asimetrías culturales y sociales (Mattelart, 2005).

Las cuestiones migratorias que aquí referimos están centradas en espacios territoriales concretos, a la vez que condicionadas por dinámicas globales y desnacionalizadas, relevantes para comprender los flujos y éxodos migratorios actuales, entendidos estos como una forma de microestructura de lo global en un marco local, más allá de la estructura del estado-nación. Estas cuestiones se deben investigar como nuevas formas de migración transnacional (Sassen, 2007). Para entender este fenómeno cabe ir más allá de concepciones puramente locales, las cuales se ven afectadas por cuestiones de desterritorialización, reterritorialización, y de las problemáticas socioculturales de la modernidad mundializada, lo que no significa el fin del territorio como referente cultural, sino la aparición de una territorialidad dilatada (Ortiz, 2002: 63). Entender este fenómeno en toda su amplitud. Un fenómeno que exigiría más transversalidad metodológica de la utilizada en este artículo. Condicionado especialmente por la «globalización económica» provocadora de la homogeneización o estandarización transcultural.

Por otra parte, la diversidad cultural debe considerarse en contextos diferentes: (i) desde el autóctono o territorial, que supone una diversidad interna (culturas diversas en una misma comunidad), como sociedad local autónoma, y a la vez como sociedad de acogida de inmigración; (ii) y desde el ámbito global y transnacional. La diversidad está condicionada por la creciente «globalización», con nuevas minorías y derechos, lo que implica la relocalización de las culturas locales o vernáculas ${ }^{3}$, formando parte de estas minorías la fuerza del trabajo de las economías precarias, sumergidas, complementarias y de servicios.

En este trabajo se estudian las problemáticas de inclusión de mujeres pertenecientes a etnias originarias y mestizas de tres comunidades de migrantes en Mallorca (Ecuador, Bolivia y Colombia) contextualizando su particular proceso de incorporación precario en la sociedad receptora, la cual está caracterizada por agrandar también la brecha entre las propias mujeres inmigrantes (Ruiz, 2002: 88-97), y que emana de la confluencia de ser mujer migrante de determinadas etnias segregadas y minorizadas ya desde sus países de origen. Los factores clave que han forzado a dichas mujeres a salir de sus tierras (etnia y género) se siguen utilizando en las tierras de llegada para sobre-rentabilizar su contribución al mercado de trabajo en Mallorca, sobreminorizándolas, y segmentando aún más las posibilidades de estas mujeres migrantes en su infraincorporación laboral. Son instrumentalizadas para conseguir su rentabilización económica por parte de la patronal, a la par que se olvida su derecho a un trabajo digno, aunque su trabajo resulte eficaz y digno (Parella, 2003: 85-113). Y ello a pesar desempeñar un trabajo muy necesario y eficaz.

La reproducción de desigualdades ocupacionales en el caso del género y de la inmigración viene marcada por el aumento de la feminización de los flujos migratorios destinados a una economía en precario que ocupa básicamente una mano de obra femenina garantizándoles únicamente la supervivencia (Sassen, 2003: 49-80; Sassen, 2004: 63-88; Sassen, 2007: 165-204), ya sea por reagrupamiento familiar (Ribas, 2004: 116-124), ya sea por la iniciativa personal de la mujer. Esto incide directamente en que los trabajos remunerados de las mujeres inmigrantes mayoritariamente sean el cuidado de niños, de personasenfermas,

\footnotetext{
3 Estas son expresiones, utilizadas por Homi K. Bhabha (2013), que nos ayudan a entender los efectos socioculturales de la «globalización» y «glocalización» posmodernas.
} 
servicio doméstico, limpieza de hoteles o edificios y agricultura (Castells y Subirats, 2007), es decir, ocupaciones precarizadas, que consolidan su condición de vulnerables, y engrosan las nuevas formas de discriminación sociocultural, política y económica. Esta situación persiste en la actualidad a pesar del crecimiento de la inmigración (Doblas, 2018: 2018/06/26/1009333) y, a partir de 2016, por la recuperación del crecimiento económico, alcanzando niveles anteriores a la crisis, concretamente por el empuje del sector turístico en las islas.

Hoy en día se presta una nueva o renovada atención en las Ciencias Sociales a la constitución dialógica y narrativa de las identidades, a los discursos como prácticas de deliberación, planteamientos centrados en la negociación de elementos compartidos sobre las diversidades multiculturales, no en contra de ellas, a pesar de que el diálogo entre las partes para poder lograr políticas más integradoras en un sentido intercultural e igualitario se encuentra muy mermado, dificultándose la convivencia desde la ciudadanía completa. También cabe considerar las posibilidades y la eficiencia, aun no demostrada, del sistema educativo (sistema escolar en concreto) para conseguir, como mínimo, que este sea puente entre culturas diversas (Lovelace, 1995: 47; Santos Guerra, 1999: 88-97). Objetivo hoy inalcanzado debido a que se mantieneun modelo asimilacionista obsoleto en el marco de las necesidades de adecuación exigida por los procesos de modernización de las estructuras del estadonación en crisis, lo que imposibilita políticas reales de educación inclusiva.

Metodología

Para visibilizar y mostrar el ensamblaje de las desigualdades de género en el marco de la diversidad cultural, en un contexto de multiculturalidad transcultural jerarquizada, acotamos el fenómeno desde las estructuras macrosociológica y microsociológica. Macrosociológica por cuanto se consideran el fenómeno de la globalización, el sistema económico capitalista actual y los valores y principios neoliberales que lo sostienen. Microsociológica al acotar el fenómeno en el espacio determinado de Mallorca y tener como unidad social de análisis un grupo de mujeres con características determinadas.

Los datos resultantes para la posterior interpretación y análisis del objeto de estudio han sido obtenidos tras aplicar técnicas cualitativas y cuantitativas como son las entrevistas en profundidad, y los cuestionarios planteados con preguntas cuyas respuestas son cuantificables. Además, se ha aplicado la técnica descriptiva a través de la exposición de estadísticas.

Las diversas entrevistas fueron efectuadas de manera presencial a mujeres procedentes de Ecuador, Bolivia y Colombia.

Elementos demográficos explicativos de las características de las Illes Balears como sociedad del bienestar y de inmigración

El crecimiento demográfico en el territorio de las Illes Balears, consecuencia del dinamismo de los flujos migratorios, ha sido una constante digna de resaltar, en especial antes de la crisis global de finales de 2008. En el año 2006 se superó por primera vez el millón de habitantes y el crecimiento prosiguió hasta alcanzar su máximo nivel en el año 2012 (IBESTAT, 2018). En este sentido, 2012 resulta clave para explicar la situación actual de las islas como momento álgido de la inmigración y del desarrollismo, en especial en los sectores del turismo y la construcción, complementados con el sector servicios, sectores que definen el tipo de sociedad concreta que estudiamos, como sociedad del bienestar capitalista dependiente de la globalización y del mercado.

Podemos apreciar que la presión sobre el territorio, en un espacio relativamente corto de tiempo, ha sido muy importante, con un incremento desde el año 1996 del 46,8\% de la población (Illes Balears 1996: 760.374 h y 2019 1.149.460. INE, 2020: 1/01/2020, 2860). La llegada masiva de inmigrantes a las Illes Balears es el principal causante del incremento poblacional (Europa Press, 2019: 25/06/2019, 1.090.105). Constituye un actor más de la presión sobre el territorio (consumo de territorio, sin olvidar otros factores de crecimiento desarrollista como el urbanístico). Tiene consecuencias en la organización del conjunto de la vida de la comunidad y en el uso de los recursos, ya que implica más servicios sanitarios, educativos y sociales, y más presupuesto para cubrir gastos de estos servicios. Por otro lado, el contexto económico-capitalista exige más mano de obra barata y la precarización del trabajo para poder mantener el ritmo de crecimiento estipulado y ser rentable. Puede también verse en sentido positivo como cambio ecológico urbano, cambios dinámicos en el empleo e incremento de impuestos para mantener el estado de bienestar. Más allá del impacto cultural en los primeros pasos del impulso inmigratorio, posibilita una sociedad más dinámica multiculturalmente hablando (González Pérez y Somoza, 2004: 22/6/2004, 25547), aunque las políticas oficiales socioculturales y económicas, en general y a pesar de encontrarnos en un estado denominado del bienestar, resultan seguramente insuficientes (Vallespir, 2006: 53-80).

Si analizamos los datos disponibles en el Institut d'Estadística de les Illes Balears (IBESTAT, 2018), podemos relacionar la variación porcentual del incremento de población que han experimentado las Illes Balears con la llegada de inmigrantes. Iniciamos este estudio demográfico con unos porcentajes residuales de población extranjera en el año 2008, con un 4,8\% sobre el total de la población, y se llega a porcentajes que nos sitúan entre las comunidades que más extranjeros tiene en su padrón, 21,9\% en el año 2012. El número de inmigrantes residentes en las islas ha retrocedido circunstancialmente estos últimos años debido al retorno de un buen número de ellos a sus países de origen, aunque en la actualidad el flujo de retorno se ha ralentizado, probablemente por una cierta estabilización de la crisis y cierta revitalización económica.

La mayoría de inmigrantes que residen en las islas son de procedencia europea (53,1\%); el segundo contingente de personas llegadas al archipiélago lo forman los sudamericanos $(21,9 \%)$, siendo los africanos los terceros (18,4\%).

Si nos fijamos en la distribución de la población extranjera en las islas comparada con la población extranjera en el ámbito del Estado español, para poder comprender así el lugar que ocupan las Illes Balears en este contexto receptor, que cada vez más 
se puede definir como sociedad de "acogida y multicultural», detectamos que una de las características de la modernidad reciente isleña es la incorporación de población extranjera.

Vemos que en la distribución de población extranjera hay diferencias entre los territorios. El peso de la población europea es mucho mayor en las Illes Balears que en el resto del territorio estatal, un 49,6\% en las islas y un 43,2\% en el conjunto del Estado, aunque en ambos es el grupo mayoritario cuantitativamente, pero minoría en el sentido discriminatorio y desigualitario en relación a los derechos humanos, lo que cuestiona su ciudadanía de pleno derecho.

El peso de la población sudamericana en las Illes y en el período que analizamos ha estabilizado sus porcentajes, pero aun así sigue consolidándose su potencial demográfico y ecológicohumano. Las ratios de la población colombiana, ecuatoriana y boliviana pueden observarse en la siguiente tabla:

Tabla 1: Población colombiana, ecuatoriana y boliviana y peso sobre la población extranjera

\begin{tabular}{|l|c|c|}
\hline & $\begin{array}{c}\text { Número total } \\
\text { de personas }\end{array}$ & $\begin{array}{c}\text { \% sobre el total } \\
\text { de la población }\end{array}$ \\
\hline Población extranjera & 186.933 & 16,8 \\
\hline Población colombiana & 14.797 & 7,9 \\
\hline Población ecuatoriana & 14.698 & 7,9 \\
\hline Población boliviana & 6.000 & 3,2 \\
\hline
\end{tabular}

Fuente: elaboración propia con base en la información obtenida de IBESTAT (2018).

Los tres países tienen un peso importante en la distribución de población extranjera en las islas, alcanzando entre ellos un $18,97 \%$ sobre el total. La población colombiana y ecuatoriana tiene porcentajes similares, en torno al 7,9\%, y la población boliviana es la menos representativa demográficamente de las tres, con un $3,2 \%$.

Las cifras de emigración de Ecuador hacia el exterior que podemos ofrecer se resumen en el gráfico siguiente:

Tabla 2: Distribución de la población ecuatoriana emigrada por sexo

\begin{tabular}{|c|c|c|c|c|}
\hline Años & Hombres & Mujeres & Total & $\%$ \\
\hline 2017 & 535.545 & 595.882 & 1.131 .427 & 6,8 \\
\hline 2015 & 524.323 & 580.857 & 1.105 .180 & 6,8 \\
\hline 2010 & 556.913 & 596.986 & 1.153 .899 & 7,7 \\
\hline 2005 & 479.550 & 508.467 & 988.017 & 7,2 \\
\hline 2000 & 217.484 & 228.280 & 445.764 & 3,6 \\
\hline 1995 & 159.426 & 166.160 & 325.586 & 2,8 \\
\hline 1990 & 105.553 & 108.178 & 213.731 & 2,1 \\
\hline
\end{tabular}

Fuente: elaboración propia con base en la información obtenida del diario Expansión, 2018.
Como se ve, y a pesar de la disminución de emigrantes ecuatorianos/as desde 2010, la tendencia a la feminización migratoria persiste. También se detecta una recuperación general de la emigración en 2017. Según indica la ONU en diario Expansión (2018), aunque sus cifras no coinciden exactamente con el cuadro del diario Expansión (2018), en Ecuador existen 1.101.923 emigrantes, es decir un $6,8 \%$ de la población. Esto significa un porcentaje emigratorio medio, ya que figura en el puesto 102 de los 194 de la clasificación de emigrantes presentada en 2015. De todos ellos, las 581.635 mujeres suponen un 52,8\% del total de emigrantes y los 520.288 emigrantes varones constituyen el $47,2 \%$.

Según datos del diario económico digital Expansión (2018), aunque el destino prioritario de la emigración de Ecuador es Estados Unidos, con un 40,2\%, España es el preferido de Europa, $38,30 \%$, seguido a mucha distancia de Italia, con un $8,0 \%$. La emigración ecuatoriana últimamente ha disminuido en 32.119 personas, el 2,8\% (en 2017). Esta disminución no afecta a la continuidad de la feminización migratoria, que es una de las características que llaman la atención como elemento definitorio del éxodo migratorio transnacional del Ecuador.

Por otra parte, el padrón de habitantes de 1 de enero de 2018 indica que la población alcanzada en las islas es de 1.128.139 (Instituto de Estadística Estatal). En dicho padrón se registra una tasa de $17,1 \%$ de origen extranjero, y el colectivo más numeroso es el de Colombia, 7.461 personas (Guijarro, 2018: 8), lo que significa un aumento considerable de población en su conjunto con respecto al 1 de enero de 2017 (crecimiento del 1,1\%), siendo la comunidad con más crecimiento de población extranjera de toda España. Si consideramos, como indica F. Guijarro (2018: 8), que el crecimiento medio de la población en España a lo largo del año 2017 ha sido del 0,3\%, en el archipiélago el aumento del número de residentes cuadruplica el estatal. Esto puede significar un impulso de la economía, que volvería a ofrecer atractivo laboral (Guijarro, 2018: 8), lo que parece indicar a su vez que se va remontando la crisis y que las islas vuelven a ser reclamo de trabajadores/as de ámbito transnacional, sin dejar por ello de estar exentas de conflictos globales y locales.

Los barrios donde más crece la población en Palma son los más precarios, como Pere Garau, Foners y Camp Redó, entre otros (Ara Balears, 2018). Por otro lado, cabe destacar además que la problemática sanitaria, consecuencia de la retirada de la tarjeta sanitaria a los inmigrantes considerados ilegales persiste en 20184. La prolongación de la crisis en el tiempo desde 2008, en especial alrededor de 2012, ha propiciado también un cambio en las nacionalidades del retorno, de manera que las personas que primero solicitaron la vuelta fueron de ciudadanía boliviana (últimas en llegar y que, por tanto, no habían tenido tiempo de regularizar su situación). Posteriormente, el interés en el retorno se extendió a ciudadanas y ciudadanos de Ecuador, Argentina, Uruguay y en menor medida de Brasil, Colombia, Venezuela y Chile (Cortés, 2012: 25 de junio, s/p).

\footnotetext{
${ }^{4}$ Aunque también es cierto que el Tribunal Supremo del Estado español ha anulado la entrega de la tarjeta sanitaria a las personas sin papeles que se aplicaba desde 2015 a propuesta del Gobierno de las Illes Balears. A pesar de ello, la Conselleria de Salut ha seguido asistiendo a los «sin papeles» de manera universal. (V.S. y S.C., 2018 16) En junio de 2018, el nuevo presidente del Gobierno español, Pedro Sánchez, anunció la reimplantación de la cobertura sanitaria universal.
} 
Contexto sociocultural migratorio transnacional en un contexto de sociedad receptora

La realidad sociocultural de las sociedades de origen (Ecuador, Bolivia y Colombia) se encuentra, respecto a la diversidad cultural y a pesar de su pluralidad, en un claro deterioro, transculturación y proletarización. Si bien, en general, en toda América Latina emergen movimientos originarios y afroamericanos, éstos son engullidos paulatinamente por la estandarización cultural propiciada en gran medida por la globalización. A esto hay que añadir las situaciones de exterminio propiciadas por la colonización y la «glocalización» de los fenómenos culturales concretos, lo que propicia, junto con una desterritorialización ya citada, la necesidad de impulsar una reterritorialización adecuada a las exigencias de estas dinámicas tan potentes, que afectan directamente a la vida cotidiana de las personas en un territorio determinado (Chomsky, 2003; Ortiz, 2002; Clastres, 2002: 55-63).

Trabajamos en un contexto de emigración desde Suramérica (Ecuador, Bolivia, Colombia), con unas sociedades con dificultades de desarrollo económico y social, hacia una sociedad que, al menos antes de la crisis, ofrecía un cierto «bienestar capitalista» con sus propias limitaciones, es decir haciendo hincapié en una economía de servicios y de financiación. Según Mónica Tapia (2014: 9-29), la migración presenta las siguientes características:

1) La diversificación de los lugares de destino de la migración latinoamericana. A los destinos tradicionales (migración fronteriza intrarregional y Estados Unidos) se han incorporado, en los albores del siglo XXI, algunos países de Europa, principalmente del Sur. Unos conjuntos de factores contribuyen a explicar esta multipolaridad de los flujos migratorios latinoamericanos.

2) Los flujos migratorios de ciertos países andinos como Bolivia y Ecuador pasan a ser masivos. Existe una gran diversidad y heterogeneidad de colectivos migrantes. Un elemento nuevo es la presencia significativa de mujeres que migran a países de Europa del Sur para trabajar en las actividades de cuidado de ancianos y niños.

3) La feminización de las migraciones pone en la agenda la cuestión de la reproducción social a escala global y la necesidad del estudio de las familias transnacionales y el ejercicio de la maternidad a distancia (Nyberg y Vammen, 2016: 191-220)

4) Diversas evidencias empíricas han demostrado que el migrante es un actor con posibilidades de involucrarse económica, política y culturalmente, tanto en la sociedad de destino como en la sociedad de origen (Tapia Ladino, 2014: 9-29).

Por otra parte, el factor lingüístico como factor cultural a tener presente -el idioma español, aunque la lengua catalana es cooficial-, el consumo y las formas de relación familiar y de ocio no provocan una «guetización» tan acentuada como puede darse en la población magrebí o la subsahariana, instaladas con anterioridad en diversos núcleos de Mallorca, comunidades consideradas poco o nada modernizadas según los parámetros vivenciales utilizados por la población autóctona más urbanizada, aunque esta sea fruto de la modernidad reciente. (Melià, 1997; 2004: 15-19)

En las Illes Balears aparecen entrecruzadas cuestiones sociológicas diversificadas, como clase social, exclusión social, racismo, xenofobia, explotación socioeconómica o precariedad laboral, que se manifiestan en una sociedad conflictiva y contradictoria (Justicia i Pau, 1992). Hablamos de un contexto subsumido, de transculturación jerarquizada, hibridación asimétrica y mestizaje cultural obligado o impuesto, de estandarización de la cultura dominante y piramidal como parte de la estrategia homogeneizadora del capitalismo postindustrial, de pérdida de identidades y de culturas que viven procesos de extinción, así como de reacciones en contra de este proceso y a favor de una recuperación identitaria y cultural, como elemento cohesionador de la sociedad local para poder relocalizar y reterritorializar democráticamente las culturas de forma que estas recuperen progresivamente el control de su protagonismo en sus distintas manifestaciones individuales y colectivas (Bauman, 2002: 143-144 y 304-305).

Nos referimos a una diversidad cultural hibridada, desnaturalizada y artificiosamente construida desde el poder, ya sea político o económico, en un marco de tensiones y procesos transnacionales de desigualdad de poder, prestigio y recursos materiales, asociando las capas de población inmigrada a la pobreza y precariedad, donde el sistema educativo institucional, tal y como está estructurado, poco protagonismo puede ejercer, incluyendo el marco institucional en el sentido de poca capacidad profesional y material y de ir más allá de lo políticamente correcto, a pesar de los muchos esfuerzos para impulsar acciones de inclusión educativa, aunque sistemáticamente no se ha resuelto más que en un sentido de multiculturalidad limitada, que segrega y dispone de una exigua comunicación intercultural (Grimson, 2011: 241), quedándose en un planteamiento de multiculturalidad asimilacionista neoliberal, es decir, a remolque de la cultura oficial estatal y a merced de los planteamientos capitalistas.

Se trata de un contexto de crisis, especialmente dolorosa para las clases medias más débiles y la clase trabajadora en general, así como para las minorías étnicas, donde las ofertas educativas cada vez son menos inclusivas, con menos conciencia de la desigualdad étnica, división sexual del trabajo y aumento de la discriminación sanitaria (Villarruel, 2012: 2012/20/1/1360. En el contexto escolar de la ciudad de Palma (Mallorca) se pueden ejemplificar situaciones como retratos sociológicos de minorías con diferencias socioculturales: inmigrantes magrebíes, subsaharianos, iberoamericanos y diversos grupos de gitanos. Este entorno de cultura urbana también funciona en otros municipios urbanos o rurales de la parte más tradicional de la isla, por lo que se puede encontrar un nexo entre la problemática multicultural y la cuestión de la identidad cultural en Mallorca.

Por otro lado, los derechos humanos denominados de segunda generación (Valencia, 1998: 46-50 y Artículo 22 de la Declaración de los derechos Humanos) (derechos económicos, sociales y culturales), superadores de desigualdades en el ámbito de la salud, la educación y la cultura, que el estado de bienestar pretendía potenciar en un marco de igualación de 
oportunidades, han quedado en entredicho (González, 2017: 22-12-2017, 157341). Los derechos colectivos y de los pueblos son los derechos llamados de tercera generación, y junto a los derechos de las minorías de no discriminación étnica (Alonso Iglesias, 2003: 65-66 y Valencia, 1998: 50-54) que deben plasmarse en el contexto social concreto, son ignorados o son de dudosa aplicación.

Para las mujeres inmigrantes la distribución de oportunidades no es equitativa y es en consecuencia asimétrica, teniendo presente que la igualdad de oportunidades equitativas es un derecho ligado a tener un trabajo, una vivienda digna y unos servicios sociales ofrecidos por el estado de bienestar vigente para la mayoría de la población (Beck y Beck-Gemsheim, 2008: 21-39). Esto, en muchas ocasiones, no se cumple en las capas más vulnerables, en especial en momentos de crisis, en que las hipotecas sobre las viviendas son un lastre para muchas familias con trabajos precarios e inestables o incluso en el paro o sometidas a reducción de salario. Aunque el salario sea superior al que tendrían en la sociedad de origen, resulta inferior al de los pobladores de la sociedad de acogida del mismo nivel sociocultural-académico, lo que indica que se pone en cuestión el derecho al salario digno.

Precarización, racismo y xenofobia suavizados que afecta muy directamente a estos grupos étnicos en Palma (Mallorca)

El discurso sobre los conceptos de migración y multiculturalidad (Rodrigo Alzina, 2005: 73-83) a menudo se realiza desde una perspectiva políticamente correcta (Agrela, 2002: 115), obviando la realidad de que las minorías subalternas representan: pobreza, precariedad o subsistencia, en especial en el caso de la mujer migrada (Puigvert, 2013: 57-69). Así, nos encontramos con que la mujer como inmigrante se encuentra inserta en una economía de precariedad, de servicios, de exigencias en el trabajo propias de un técnico/a cualificado/a, a la vez que se abusa de su necesidad urgente de trabajar.

La multiculturalidad tratada en este contexto deviene en una distancia cultural a través de los estereotipos negativos étnicos, y de las fronteras simbólicas heredadas del asimilacionismo imperante, donde la minoría es estigmatizada. Además, la diversidad cultural resulta poco respetada y es ignorada, tanto por lo que respecta a las minorías internas del estado-nación (etnias minoritarias y comunidades nacionales), como por las referidas a las externas a través de la inmigración (Merino, Rabalda, 2012: 170-174; Grimson, 2011: 135-169).

Después de un proceso migratorio inicial, donde la masculinización resultaba bastante clara (Ecuador, Bolivia y Colombia), en poco tiempo, la migración hacia Europa dio un giro significativo hacia una fuerte feminización. La perspectiva de género, diferenciando entre hombres y mujeres, permitió conjugar las explicaciones económicas como principal motivo de la emigración con otro tipo de factores como los conflictos familiares, la violencia doméstica y la discriminación étnico-social.

Por otra parte, en el caso concreto de la emigración a Mallorca, el hecho de instalarse en la isla más mujeres que hombres provoca que la socialización formal se complete en el ámbito familiar exclusivamente por el papel de las mujeres, perpetuándose así la función socio-cultural que se les asigna y que ellas asumen como normal. La permanencia de estas mujeres en Mallorca, muy probablemente, se explica también por la responsabilidad que se les ha asignado: el cuidado, socialización y educación de los hijos e hijas en edad escolar (infancia y adolescencia) de la población «autóctona» mallorquina y por la perfecta simbiosis de este rol con la interiorización por parte de las mujeres de este «Compromiso» de cuidadoras (Castells y Subirats, 2007: 226 y 119 122; Díaz Gorfinkiel y Martínez-Buján, 2018: 105-118). Por otro lado, desde la población autóctona se interpreta, en no pocas ocasiones, que los culpables del aumento del paro y de la pobreza (Cursat y Ibáñez, 2013: 153-163), vividos como perjudiciales para los intereses de los «autóctonos» y capas subalternas «preestablecidas» e incluso población inmigrante anterior, son los migrantes dispuestos a ocupar puestos de trabajo con menos compensaciones económicas, esto es, como mano de obra aún más barata.

El racismo y la xenofobia, silenciados o suavizados, se instalan en la posición de las culturas subalternas y minorías étnicas en situación de desventaja y en procesos de segregación, discriminación y vulnerabilidad más o menos forzada por las dinámicas de la realidad, en un contexto formalmente democrático. Al amparo de una aparente cohesión social predominan, en estas comunidades, fórmulas de adaptación o de integración desde el asimilacionismo institucional paternalista envuelto por una cultura de la apariencia, poco democrática y desigualitaria. Existen barriadas palmesanas como Son Gotleu (Marina,2018:29), que son objeto de criminalización, pobladas por inmigrantes extracomunitarios y minorías étnicas como la gitana, ignorándose su diversidad y convivencia. El racismo que aflora está más en los medios de comunicación de masas que divulgan los hechos, por la agresividad y violencia del lenguaje utilizado, que en las personas que protagonizan dichos acontecimientos. En la última década, las historias de conflictividad y sensacionalismo en Son Gotleu se repiten intermitentemente: por ejemplo, en marzo de 2016 se detuvo a un supuesto yihadista (Malagón, 2016: 2016/26/4), que fue posteriormente absuelto, por creer que colaboraba con el CNI (Esteban, 2017: 2017/10/11, 298787); en febrero de 2018 en esta barriada palmesana se realizó una gran operación contra la venta de drogas y la inmigración ilegal (Ollés, 15 de febrero de 2018):

En la operación Lagos, los agentes están registrando una decena de locales, como bares, peluquerías y tiendas, que, según sospechan, podrían ser utilizados para distribuir estupefacientes. Está previsto que el operativo se prolongue

\footnotetext{
${ }^{5}$ Cabe tener presente la noticia de 18 de febrero de 2018, que expresa la criminalización de estos contextos mezclándose con intereses urbanísticos ocultos: «Los clanes de narcos de Son Banya se trasladan a Son Gotleu, Marratxí y Llucmajor, el desalojo total de la etnia gitana de Son Banya es inminente. Es constante la criminalización de esta barriada, poblada por inmigrantes extracomunitarios y minorías diversas como la gitana» (Marina, 2018: 29).
} 
hasta bien entrada la noche $y$, hasta ahora, ya se ha saldado con, al menos, doce detenidos.

Todo ello nos lleva a considerar que en las políticas sociales sobre la inmigración en el archipiélago en general, y en concreto en Mallorca, se producen muchas deficiencias, entre otras la conflictividad no resuelta. Consecuentemente, la población inmigrada es llevada a situaciones límite de «guetización» de grupos de población magrebí, latinoamericana, de Europa del Este y subsaharianos. Los datos sobre la concentración (hacinamiento) de inmigrantes extracomunitarios en algunas barriadas de Palma son reveladores. Casi uno de cada tres extranjeros extracomunitarios empadronados en la ciudad reside en tan solo cuatro barriadas (Pere Garau, Bons Aires, Foners y Son Gotleu) de las 88 existentes en Palma. En la primera y la última se encuentra empadronado el $20 \%$ de las personas originarias de países no pertenecientes a la Unión Europea. Son Gotleu constituye una barriada habitada mayoritariamente por inmigrantes extracomunitarios (Capó, 2012: 11). En 2018 sigue siendo uno de los barrios de Palma más deteriorados, tanto desde el punto de vista de convivencia ciudadana como urbanístico, desarrollándose en el barrio una elevada especulación y precariedad de la vivienda de alquiler, y con insalubridad muy acentuada (Guijarro, 2019: 2019/09/12, 1447908).

En su conjunto se ve bastante necesario asignar a la educación institucional (escolar) un papel más potenciador del reconocimiento positivo de la diversidad social y cultural, para combatir una asimilación de perfil aculturador y deculturador, lo que hace que resulte discriminatorio y posmoderno, poco respetuoso con la diferencia y que ignora su papel dinamizador para conseguir una sociedad más democrática e igualitaria, casi siempre en perjuicio de las culturas minorizadas, que son víctimas de prejuicios etnocéntricos de las «culturas» dominantes e institucionalizadas por las estructuras del estado-nación (Tarabini, 2012: 289-306; Busquet, 2005: 157-163; Giroux, 2004).

La mujer afroamericana ecuatoriana como inmigrante minorizada y como ciudadana democrática incompleta en Mallorca

Aunque las desigualdades se pueden esquematizar en el marco de la estructura y estratificación sociales y según clase, género y etnia, aquí incidimos en la cuestión de la desigualdad de género y etnia, donde la mujer queda en situación de discriminación y es propensa a la exclusión social consecuencia de la división social del trabajo. La sociedad está estructurada jerárquicamente en estratos y clases sociales con una fuerte herencia patriarcal, lo que hace que se generen diversas formas de desigualdad: discriminación social y cultural, marginación, exclusión económica y social, y pobreza, en términos de clasismo y discriminación étnica con connotaciones racistas y xenófobas
(Van Dijk, 2003; Delgado, Martucelli, Actis, Palacín, Sáez, 2002; Informe anual 2018 sobre el racismo en el Estado español). Las diferencias a menudo son valoradas superficialmente, y de manera negativa si se detecta que no responden a los parámetros de la estandarización de los estilos de vida colectivos vigentes, o son contempladas como folclore fosilizado, disimulando las diferencias en la capacidad adquisitiva, el empobrecimiento en la calidad de los productos materiales, culturales y sociales, es decir, la disminución de la calidad de vida.

La cultura afroamericana en el marco de la sociedad del Ecuador multicultural tiene condición de subalterna y minorizada, aunque en su territorio estén vigentes los movimientos de resistencia contra los efectos de la colonización perpetuada y «postcolonial» (Chalá, 2001: 2 y 3). La discriminación y la exclusión social y cultural, sumergidas en la presión de la globalización y la «glocalización» (localización de la globalización y globalización de lo local) perviven entre la transculturación y la aculturación transnacional, una hibridación cultural y étnica altamente asimétrica. Por otra parte, en relación a la desigualdad étnica de origen, vemos como Franzé (Franzé, 2008) aporta un buen ejemplo de esta cultura ecuatoriana que segrega a las poblaciones africanas derivadas de los procesos de colonización y esclavitud afincadas en Ecuador: escolares ecuatorianos, con los que se estaban trabajando aspectos de multiculturalidad a través de la elaboración de un mural mediante el pegado de fotos de diversas personas de distintas etnias o mestizas, rechazaron incluir en ese cartel de la multiculturalidad ecuatoriana fotos de aquellos que no consideran ecuatorianos porque son personas negras.

Con todo, según los datos del INE, la población ecuatoriana en España se ha mantenido estable, con una cierta tendencia al descenso durante estos años de crisis económica, altas tasas de desempleo, ajustes sociales, precariedad en el empleo y malas condiciones económicas. Es decir, en 2009 había 479.117 personas ecuatorianas residiendo en España, y en enero de 2014, tras cinco años de crisis, la cifra era de 438.979 personas (Iglesias et al., 2015: 34).

En Mallorca se asiste a un aumento significativo de la población latinoamericana, con la correspondiente demanda de servicios, especialmente de educación y sanidad, lo que origina brotes de xenofobia y conflictividad (Justicia i Pau, 1992). Hay que recordar que Mallorca a partir del boom turístico de los años 60 pasó de ser una sociedad de emigración a transformarse en una sociedad receptora (Salvà, 1985), primero de inmigración proveniente de la península ibérica y a finales del siglo XX y principios del XXI de inmigración extracomunitaria (norteafricana, subsahariana, europea del Este y latinoamericana: ecuatoriana, argentina y colombiana).

Este tipo de discriminación debe entenderse como un hecho social y cultural fruto de los contextos socioculturales vividos según la cultura (y subculturas), y no como un fenómeno natural ineludible. Aunque en el sistema social y escolar se hayan dado pasos para superar situaciones de discriminación, en la sociedad dominante -especialmente en las más capitalistas- el tema de la igualdad se considera un tema menor, se sigue considerando que lo importante es la competitividad, perspectiva que a menudo genera un individualismo insolidario (Busquet, 2005: 73-83).

Para las inmigrantes ecuatorianas (afroamericanas, originarias y mestizas), una de las principales preocupaciones actuales 
detectadas a través de los cuestionarios contestados es su trabajo y la situación económica de sus hijos e hijas.

Otra de sus preocupaciones fundamentales tiene que ver con la educación de sus hijos y con la «escuela» en particular, puesto que es uno de los principales medios sociales que los vincula con la cultura de la sociedad de acogida. En este sentido, detectan dificultades de relación educativa y de adaptación a un nuevo sistema escolar. En general, los colectivos inmigrantes son los que menos pueden movilizar los recursos necesarios para conseguir logros escolares. Su cifra de abandono escolar es muy superior al de los colectivos de personas autóctonas (Castel, 2010; Juliano, 1993: 46-72).

Como ya hemos indicado anteriormente, para estas mujeres, una de las preocupaciones más significativas es la educación de su descendencia, cuya adaptación a un nuevo sistema escolar y la relación educativa consecuente resulta difícil. Se observa en las respuestas de estas mujeres el deambular de sentimientos encontrados y contrapuestos de identidades compartidas, que supone vivir unas veces según su idiosincrático estilo de vida de procedencia y otras según el de la sociedad en que les ha tocado vivir, es decir, una sociedad receptora que a menudo no tiene claro que también es de acogida de los recién llegados/as para que puedan convivir en términos de igualdad.

Entre las causas que favorecen la emigración y el éxodo, según las propias protagonistas, cabe destacar:

- El deseo de alcanzar un nivel de vida económico mejor para ellas y su familia, en especial de su prole, ejerciendo a menudo como cabeza de familia monoparental y con aislamiento social como parte del proceso de «guetización» de las zonas urbanas periféricas.

- Conseguir la salida o «liberación» de las mujeres de la red familiar, en un mundo donde el papel del hombre es considerado superior en la estructura jerarquizada del patriarcado, y donde se culpabiliza a la mujer del desarraigo familiar minusvalorándolas.

- Superar el machismo y violencia sexista todavía imperante en no pocos contextos, incluyendo el europeo, propiciado por las formas de socialización tradicional y discriminatoria, no superadas, que conllevan el papel preponderantemente educador y socializador de la mujer.

Por otra parte, el salto migratorio inicial de estas personas afroamericanas se da, normalmente, hacia Guayaquil o Quito, dos zonas urbanas con barrios de población negra procedente de Esmeraldas, que tiene connotaciones de sociedad rural tradicional y pesquera. Las personas afroamericanas recalaron inicialmente en Esmeraldas y en el Valle del Chota, ciudades originarias de los esclavos llevados por los colonizadores españoles. De todas formas, en su conjunto el origen migratorio de Ecuador es diverso, reflejo de su propia diversidad territorial multicultural, cultural y étnica, a menudo ignorada y discriminada.

Por ejemplo, podemos explicar la situación vivida por una mujer afro-ecuatoriana de 40 años y solo con estudios primarios, nacida en Esmeraldas y que inicialmente emigró a Quito. Era la cabeza de una familia monoparental, con dos hijas y con vivienda de su propiedad en Mallorca, después de mucha precariedad y comosigno de mejora dela calidad devida. En sus propias palabras:
«Mi llegada a Mallorca fue motivada por buscar una estabilidad económica que me permitiera un futuro mejor que el que podía tener en mi país. Pasado el tiempo he conseguido un trabajo permanente» (Entrevista personal 1, mujer afroecuatoriana de 40 años, 2013 y 2016). Esta persona tuvo que dejar este trabajo, dedicado a la limpieza, por un accidente laboral; aunque, después de estar en el paro, volvió a trabajar con contrato relativamente estable en una empresa de limpieza, alcanzando una estabilidad media. Según aseveraciones y vivencias de esta mujer, residente en Son Gotleu y Verge de Lluc, «a pesar de que el trabajo es duro y me llena de renuncias y sacrificios y de una sensación de cansancio constante, mantengo muchos ánimos para continuar luchando» (entrevista personal 1). Los otros trabajos que esta persona ha venido desempeñando están relacionados con el cuidado de personas mayores o enfermas, así como trabajos en precario y discontinuos en hoteles diversos.

Otra de las mujeres entrevistadas, también ex-habitante de Son Gotleu, ha pasado por momentos difíciles, como estar en el paro, situación a menudo fuente de criminalización para estas mujeres. Se trata de una mujer afroecuatoriana de 34 años desgraciadamente fallecida dos años después, dos hijos y una situación familiar complicada derivada de la precariedad del paro, que comparte con otras personas que componen en estos momentos su grupo de convivencia. Esta persona experimentó situaciones extremas y de retorno, a veces forzoso, de las que informa de la siguiente manera:

Conozco algunas personas que han retornado por falta de trabajo y por no poder pagar la vivienda ni mantener el hogar ni a los hijos». Se manifiesta muy preocupada por la situación de los hijos: «Cuando se retorna con hijos pequeños o adolescentes que han nacido y crecido aquí, en Mallorca, es muy difícil que se adapten a la vida de allá. Les afecta mucho el cambio. Es casi lo mismo cuando ocurre viceversa de allá a aquí. Lleva un proceso para integrarlos otra vez porque todo cambia (Entrevista 2 personal a mujer afroecuatoriana de Ecuador de 34 años, 2013).

Esta persona vivió con la preocupación constante de la amenaza de la precariedad y el paro, cuestión extensible a otras personas componentes del grupo familiar, con una gran inseguridad de futuro que han tenido que superar.

Una de las razones para emigrar que esgrimieron estas mujeres fue el reagrupamiento familiar. Es el caso de una mestiza ecuatoriana de 39 años de Manabí, en el sur de Esmeraldas, que vive en Son Cladera, quien también considera complicado el retorno ya que «hay que mirar la situación de los hijos» (entrevista personal 3) por los cambios culturales y emocionales. Otra mujer mestiza de 25 años procedente de Guayaquil y que vive en el Rafal Nou, considera una dificultad el retorno de los hijos que nacen en Mallorca, ya que se acostumbran a la vida de aquí y su vida está aquí (entrevista personal 4). Piensa igual que otra mujer que se define como mulata, de 42 años y que vive en Rafal Nou procedente de Guayaquil (entrevista personal 5). En 2018, una vez pasado lo más intenso de la crisis económica, las últimas entrevistas realizadas a mujeres ecuatorianas reflejan que 
la situación laboral actual les ha devuelto una cierta estabilidad. Así lo afirma una ecuatoriana de 38 años de Naranjito (que se define como mestiza) residente en una vivienda de su propiedad en la barriada de s'Indioteria de Palma, con un trabajo estable (entrevista personal 6), así como una mujer ecuatoriana de 44 años (que se define como mestiza de Manabí) de la barriada de Son Cladera quien, a pesar de que su hermana tuvo que volver a Ecuador por la crisis, considera que las condiciones de vida son aceptables

Culturalmente hablando, su nivel de catalán es bajo, dato reconocido por todas las mujeres entrevistadas, lo que dificulta su inclusión como ciudadanas de pleno derecho, incluso cuando su nivel educativo alcanza títulos universitarios como Enfermería o Administración de Empresas. Algunas de estas mujeres tenían estudios primarios y otras secundarios. En todo caso, su preocupación primordial es mantener el trabajo para sostener a su familia y los estudios de sus hijos e hijas. La mayoría no llega a $800 €$ al mes o a duras penas al salario mínimo, cuando no están en el paro o trabajan en la economía sumergida. Con estos ingresos deben afrontar los gastos de alquiler o hipoteca y el sustento y educación de sus hijos. También viven otras formas de presión discriminatoria, vivir en barrios infradotados de servicios sociales y educativos, por ejemplo, que pueden afectar negativamente a la convivencia de esta población inmigrada y en el deterioro de su calidad de vida en su conjunto, no solo económica, sino también social, política y cultural, lo que afecta a su incorporación a la sociedad pretendidamente de acogida (Bauman, 2017: 7-30 y Bohórquez, 2017: 23/05/2017, 1495539208_562530). Se les dificulta el reconocimiento como trabajadoras de derecho.

Podría suponer una ayuda para la incorporación correcta de los inmigrantes y su progresiva «integración» o acogida el aprendizaje de la lengua catalana (Mirralles, González, Vidaña, Ferragut, 2009: 114-116), como herramienta de cohesión social e instrumento de incorporación, para que se reconociesen como ciudadanas de pleno derecho. En este sentido, las políticas educativas lingüística, del anterior gobierno en la Comunidad Autónoma supusieron un retroceso: la fuerza política en el poder impulsó una ley educativa uniformista, asimilacionista, centralista, clasista y conservadora, recuperando el espíritu unionista decimonónico de la construcción del estado-nación, obviando el reformismo moderno de apertura a la diversidad cultural (Parcerisa y Verger, 2016: 354-375) ${ }^{6}$.

En el marco de la modernidad del siglo XXI, la educación institucional en su conjunto se plantea en términos cada vez más multiculturales, sin llegar a reconocerse la interculturalidad democrática, comunicativa (Benhabib, 2006: 267-282) y de igualdad de género (Benhabib, 2006, 145-163). En realidad, en el ámbito del Estado español, está condicionada por una mentalidad de asimilación cultural y unionista, afectada también por tradiciones de discriminación de género difíciles de superar, con políticas sociales insuficientes (Miralles, González, Vidaña, Ferragut, 2009: 186-189; Mayoral Mateo, 2012: 221-138). La cultura predominante en la escuela es la que emana de los postulados oficiales y su adquisición se entiende como un paso hacia la asimilación social y cultural, no como un derecho humano

\footnotetext{
6 Se refiere al reformismo del Partido Popular impulsado durante la legislatura 2011 2015 en las Illes Balears, a remolque de la reforma del sistema educativo estatal Wert
}

en sí mismo y a pesar de que España sea un estado-nación «autonómico» donde las Illes Balears disponen de competencias en educación «casi» en su totalidad.

En el contenido de las entrevistas se detecta que a la mujer se le asigna un papel de servicio social o cuidado de los demás, a menudo pagado de forma precaria. Sus hijas se integran en el papel asignado en una sociedad basada en una economía de servicios, lo que afecta a su proceso de socialización. Y en la escolarización se les dirige hacia la formación profesional, a la educación infantil y al ámbito artístico, trazando el itinerario académico hacia profesiones como trabajo social, artísticas o administrativas (Castells y Subrats, 2007: 226 y 119-122; Díaz Gorfinkiel y Martínez-Buján, 2018: 105-118). Las culturas minoritarias y minorizadas se encuentran en posición de desventaja y de discriminación, todavía consideradas como «amenaza al trabajo propio, la seguridad y la cultura nacional dominante» (Giddens y Sutton, 2014: 776), lo que implica asumir la cultura oficial del estado y la local folclorizada. Su condición es la de culturas subalternas y de menor dignidad, lo que dificulta el camino hacia el pluralismo cultural, alejándose del respeto y potenciación de la diversidad cultural como derecho humano básico.

La educación y socialización pueden jugar un papel importante para implementar propuestas más interculturales a la educación formal y los diferentes niveles de socialización. En este contexto sociocultural la mujer tiene atribuido un rol relevante, máxime si se trata de una familia monoparental, en cuyo caso se erige en única cabeza familiar.

Contexto de la inmigración colombiana y boliviana en Illes Balears

Colombia, Bolivia y Ecuador son países de Suramérica, territorial y políticamente andinos, con un considerable grado de similitud, una gran parte de población originaria (Colombia y Ecuador con una comunidad negra significativa) y variedad de etnias y lenguas.

En el contexto de Suramérica, Colombia es el país que tiene mayor cantidad de emigrantes, según el Departamento Nacional de Estadística (DANE) y el Ministerio de Relaciones Exteriores colombianos, aunque los datos que conocemos son divergentes. Para DANE (2012) son 3.378.345 personas las que emigran de su tierra, pero para el Ministerio de Relaciones Exteriores el número estimado asciende a 4.700.000 (Organización Internacional para las Migraciones-OIM, 2013: 40-60).

En cuanto al número de personas que se establecieron fuera del país en 2010, Estados Unidos alberga un total de 908.734 colombianos, en Venezuela hay 684.040 y en España son 221.797, que representan el $8,1 \%$ del total de extranjeros en el país ibérico. En el caso particular de Estados Unidos, la población colombiana 
migrante se duplicó con relación a la cifra del año 2000, cuando alcanzó las 470.684 personas (U.S. Census Bureau, 2011).

En cifras, y según el Banco Mundial y datos de 2010, los colombianos/as emigradas fueron 2.122.100, lo que corresponde al 4,6\% del total de la población colombiana. Los destinos más frecuentes según este informe son Estados Unidos, la República Bolivariana de Venezuela, España, Ecuador, Canadá, Panamá, Francia, Italia, Reino Unido y Alemania (Banco Mundial, 2011).

«Los principales destinos hacia los cuales emigran los colombianos, según los datos del Banco Mundial, Estados Unidos es el primer destino, con un 28,8\%, seguido de la República Bolivariana de Venezuela, con un $28,4 \%$; en tercer lugar, España, con un 17,6\%; Ecuador, con 8\%; Canadá, con 2,1\%; Panamá, con 1,4\%; Francia e Italia, con 1,1\%; Reino Unido, con 0,7\%, y Alemania, con 0,6\% (Banco Mundial, 2011)» (OIM, 2013: 42).

Colombia resulta ser el país Latinoamericano en general y de Sudamérica en particular con mayor cantidad de emigrantes y desde la década de los noventa, España se convirtió en uno de los principales destinos para los emigrantes colombianos. Esto último motivado por la búsqueda de nuevas oportunidades y por la facilidad del idioma que hacía más sencillo el ingreso a ese país. (OIM, 2013: 42)

Según el Instituto Nacional de Estadística de España (INE), la cantidad de colombianos/as residentes en España en el año 2016 es de 135.954. Las personas nacidas en Colombia son, según el mismo organismo, 354.461, independientemente de su nacionalidad (colombiana o doble nacionalidad) (INE, 2016). Esta diferencia obedece a la adquisición de doble nacionalidad: Ecuador, Colombia y Bolivia figuran, tras Marruecos, como los países con más demanda de nacionalidad española.

Por otra parte, si nos referimos a las Illes Balears en su conjunto, notamos que según el padrón del INE de 2017 hay:

6.063 personas de nacionalidad colombiana, con presencia en al menos 24 municipios de la provincia. Por sexos se reparten en un $53 \%$ de colombianas y un $47 \%$ de colombianos, con una media de edad de treinta y seis años, cuatro años inferior a la media provincial (INE. Padrón, desde 2017 hasta el 13 de febrero de 2018).

Si nos referimos a Bolivia y observamos el país de destino de los emigrantes, podemos constatar que, en 2009 el 94\% de los emigrantes se dirigió principalmente a cinco países: España, Argentina, Estados Unidos, Italia y Brasil.

En Bolivia, en particular, pero también en Colombia y en Ecuador como países andinos, y a pesar del avance de los derechos humanos de pueblos $s$ originarios y en el caso de Ecuador también afroamericano/as, se produce discriminación étnica en sentido social y económico. Las capas de población indígena son tratadas como sinónimo de pobreza, marginación social y cultural, a pesar de su progresiva urbanización y desruralización.
Mujeres originarias de Bolivia y de Colombia en Mallorca

Como se ha apuntado en este trabajo, la inmigración procedente de Bolivia y Colombia supone un 3,2\%, y un 7,9\% respectivamente del total de población extranjera en las Illes Balears, a la par que el colectivo colombiano es el más numeroso. Palma, principal municipio de Mallorca y las Illes Balears, con 2.578 colombianos, es la ciudad que alberga un mayor número de ellos. Eivissa, Manacor, Alcúdia, St. Antoni y Ciutadella son, según datos del padrón de 2017 (INE, 2018), otros municipios con un número superior a 200 habitantes de origen colombiano.

Cuando analizamos los datos del INE sobre la variación de la población extranjera residente en España en 2016, observamos el diferente comportamiento de los colectivos colombiano y boliviano. El primero experimentó un crecimiento del 2,47\%, mientras que el segundo fue el que más decreció de los diferentes países de origen estudiados, el 15,1\%. Esto último se relaciona con las consecuencias de la crisis y consiguiente retorno al país de origen, sobre todo en el caso de los bolivianos, tratado y explicado en anteriores epígrafes (INE, 2017).

Dentro del colectivo colombiano, los datos recogidos por la Organización para la Cooperación y el Desarrollo Económicos (OCDE) en 2000 ya señalaban como el 63\% de la emigración dirigida hacia España disponía solo de estudios primarios. Este hecho se relaciona directamente con la ocupación de empleos poco o nada cualificados, mientras que, según la misma fuente, la población colombiana emigrada a Estados Unidos, poseedora de estudios secundarios o terciarios en un $72 \%$, muestra un espectro amplio en lo que respecta a la ocupación. En el caso de las mujeres colombianas asentadas en España, y en Mallorca por ser el caso que nos ocupa, el servicio doméstico constituye su principal actividad (OCDE, 2009: 247).

Aproximarnos a la mujer originaria boliviana, quechua, aimara y mestiza colombiana supone abordar la diversidad cultural enmarcándola en procesos más amplios de aculturación y transculturación ya apuntados, lo que puede definir actitudes ambivalentes de las protagonistas respecto a la enculturación indígena. Al mismo tiempo, la variable de género, unida a la condición de inmigrante precaria de estas mujeres, resulta decisiva en el destino laboral de las mismas una vez en el país de acogida (Zanfrini, 2007: 108-113).

Las 7 mujeres bolivianas y 9 colombianas entrevistadas viven en Mallorca y tienen edades comprendidas entre 19 y 60 años. La condición originaria no se manifiesta: solo en un caso se reconoció y afirmó abiertamente. Se trata del caso de una mujer mestiza boliviana que se define como aimara (referencia de la entrevista personal 7). Evitar la auto-adscripción como originaria puede ser una estrategia para evitar la doble discriminación de ser considerada extranjera e india a la vez, mientras que la auto identificación originaria se relacionaría con la etnización, asociada a la reivindicación de la cultura originaria y sus derechos (Arias Barrero y Carrera, 2014: 48-63).

El carácter mestizo colombiano se percibe con mayor naturalidad. La mayoría de las mujeres proceden de un medio urbano en el país de origen y su nivel de formación académica 
es básico, sobre todo en el caso del grupo de bolivianas donde solo la mujer que se define como aimara posee estudios secundarios. Dentro del grupo de mujeres colombianas se aprecia un mayor nivel de formación y algunas incluso iniciaron estudios universitarios que no concluyeron (3 entrevistadas de 7). La razón principal por la que decidieron emigrar es la situación socioeconómica desfavorable de sus países de origen y el deseo de encontrar mayor bienestar en el país receptor. En el caso de Colombia se cita además la situación de violencia e inseguridad del país, pues algunas han emigrado de allí porque estaban en peligro (Entrevista personal 8). El machismo y la brecha salarial entre hombres y mujeres constituyen también un estímulo para emigrar (Entrevistas personales 9 y 10). La elección del lugar concreto, Mallorca, responde en todos los casos al hecho de tener vínculos personales en la isla, lo que supone un apoyo social decisivo en el proceso de adaptación. Si bien su situación no es regular en todos los casos, todas trabajan en el servicio doméstico, limpiando y/o cuidando de personas mayores, excepto la más joven que está cursando un grado medio de Formación Profesional (Repostería) (Entrevista personal 11 mujer de Bolivia de Santa Cruz de la Sierra).

El impacto de la crisis en sus inicios supuso la pérdida de ocupaciones de intendencia desempeñadas en domicilios, y al mismo tiempo se produjo un empeoramiento general de las condiciones laborales y de salario. 7 de ellas, que aún no han podido regular su situación, comparten vivienda con otras personas inmigrantes. Todas tienen hijos, algunos se han quedado en el país de origen y otros han nacido en España. La relación con los hijos menores que se quedan en el país de origen es compleja. Los niños y adolescentes suelen quedar a cargo de una familiar mujer. A partir de los 16 años de edad puede ocurrir que se queden varios hermanos solos con la supervisión de la madre desde la distancia. La reagrupación después de años de separación también se revela compleja y a menudo conflictiva, especialmente en el caso de adolescentes (Funes, 1999: 119-144).

Valoran positivamente de Mallorca, sobre todo, el orden, la tranquilidad, la seguridad y el nivel de vida. «Aquí alcanza para vivir, allí se vive alcanzado», dice una mujer colombiana (Entrevista personal 8). Con todo, a menudo echan en falta el sentido de comunidad aún presente en sus países de origen y critican el mayor individualismo de la sociedad de acogida. Alguna explica haber sufrido tratos discriminatorios en su trabajo por ser inmigrante (entrevistas personales 7 y 12). En algún caso señalan similitudes culturales que relacionan con la aculturación (entrevista personal 7) que supuso la colonización. Aunque algunas de ellas están siguiendo un curso de catalán (entrevistas personales 8 y 13), su conocimiento de la lengua y la cultura mallorquina es escaso en general, si bien es mayor cuando han vivido en pueblos o están estudiando. Esto último no hace sino resaltar la fuerte aculturación producida también en Mallorca, reflejada en la ascendencia y predominio de subculturas urbanas, consideradas más modernas y funcionales para la adaptación. La lengua y las formas culturales propias de las Illes son contempladas como prescindibles para la adaptación y quedan relegadas. La continuidad lingüística castellana, lengua fuerte, constituye además un factor determinante en el caso que nos ocupa. De ahí que el acercamiento y el conocimiento de la lengua catalana, lengua débil y minorizada, se produzca en contextos en que su presencia está muy marcada, como es el caso de los pueblos y el contexto educativo, donde la lengua catalana es curricular.

Conclusiones finales

El contexto de Mallorca, subsidiario de la sociedad del bienestar, fomenta la dependencia económica de grandes organizaciones multinacionales y financieras, provocándose una jerarquización económica, social y cultural muy fuerte que instaura una dinámica especulativa en todos estos ámbitos (Mishra, 1994; Tort, 2019: 71-73). El medio que acoge al inmigrante debería considerar su aportación sociocultural, favoreciendo la convivencia social y la participación política democrática, acorde a la legislación de derechos humanos.

Las identidades culturales, siempre dignas de consideración, lo son más en el mundo posmoderno de lo efímero y de la superficialidad de la apariencia, que impulsa la inmediatez y no la profundidad de un cambio transformador. Por ello, se debe fomentar la necesidad solidaria de respeto entre las culturas de acogida y las desplazadas de su realidad territorial. Los fenómenos de erosión de la identidad cultural desde el punto de vista de cultura minoritaria, sin un estado-nación y del bienestar que democratice los derechos culturales de las minorías, producen desigualdad (Delgado, Martucelli, Actis, Palacín, Sáez, 2002). Se fomentan actitudes políticas, culturales y educativas uniformadoras y centralistas, que no tienden a favorecer el esplendor del arcoíris de la diversidad cultural (Naïr, 2005 , 49-78). Aunque considerando las aportaciones de autores citados anteriormente como Hall (1996/2003) o Grimson (2011), en el contexto que tratamos se quedan en identificaciones, más que un complejo de identidades se trata de identificaciones manipulables desde el poder.

Cabe hacer hincapié en las dificultades para incorporar culturalmente a las minorías étnicas no comunitarias, tarea que precisa de una apertura cultural no asimilacionista y multicultural o intercultural, culturalmente abierta y que facilite la convivencia de una ciudadanía interétnica, que no suponga la integración como una afirmación hegemónica de la cultura de la sociedad o comunidad de acogida.

También urge la superación de la actual precarización del trabajo y la discriminación por razones de género y etnia, en general, pero también en particular con las minorías inmigradas desprotegidas. Es preciso erradicar la precarización ocupacional, la pobreza, la «guetización» sociocultural, la desigualdad por género, etc. de las capas más desprotegidas de la inmigración. La amenaza de recortes en políticas sociales, en educación con inmersión lingüística y educación multicultural, y la concentración irregular de alumnos extranjeros son también inconvenientes. Hay centros educativos poco respetuosos con la diversidad cultural, lo que resulta determinante en la anómala distribución de hijos de inmigrantes en determinados centros escolares. Por lo tanto, resultan importantes las propuestas y realizaciones 
no discriminatorias en el sistema educativo. Recordemos las potencialidades educativas de las que podría disponer la escuela con una mentalidad más intercultural (Carbonell, 1994 y 2003).

Los rebrotes de racismo suave y contenido que afectan directamente a las etnias minoritarias, entre ellas las mujeres suramericanas originarias y negras, tienen consecuencias negativas para la vida familiar y para su socialización en la cultura de acogida. Es un racismo que se manifiesta a través de lo que se puede denominar como violencia suave (Bourdieu, 2000), violencia que se establece en relaciones de poder desiguales entre los miembros sociales en una estructura social jerarquizada, en este sentido L. Grossberg resume los planteamientos de S. Hall sobre este tipo de desigualdades étnicas y de género, en un contexto de poder desigual y jerarquía sociocultural (Grossberg, 2006).

Con la crisis que se vive todavía en Europa, en general, y en la isla de Mallorca en particular, es decir, con la crisis del estado del bienestar, se aumenta la desatención social de las capas más vulnerables de la sociedad, entre ellas la mujer inmigrada y su familia (Fundación FOESSA, 2018). Consecuencia de ello es que están en una situación que las hace vulnerables de ser discriminadas, silenciadas o excluidas socialmente, tanto por su etnia y cultura como por ser mujeres, dificultándose así el ejercicio de su plenitud ciudadana.
Fuentes y bibliografía

\section{Entrevistas}

ENTREVISTA PERSONAL 1 (2013 y 2016): a mujer afroecuatoriana de 40 años de Ecuador de Esmeraldas reside en la barriada Verge de Lluc.

ENTREVISTA PERSONAL 2 (2013): a mujer afroecuatoriana de 34 años Esmeraldas residía en la barriada Verge de Lluc.

ENTREVISTA PERSONAL 3 (2016): a mujer mestiza de 39 años de Ecuador (Manabí) que reside en la barriada de Son Cladera,

ETREVISTA PERSONAL 4 (2016): a mujer mestiza de 25 años de Ecuador de Guayaquil reside en la barriada del Rafal Nou.

ENTREVISTA PERSONAL 5 (2016): a mujer mulata de 42 años de Ecuador de Guayaquil residente de la barriada del Rafal Nou.

ENTREVISTA PERSONAL 6 (2018): a mujer mestiza de 38 años de Ecuador reside en la barriada de $s^{\prime}$ Endiotaria.

ENTREVISTA PERSONAL 7 (2018): a mujer aimara de 60 años de Bolivia de La Paz reside en la barriada de Porto Pi.

ENTREVISTA PERSONAL 8 (2018): a mujer de 49 años de Colombia de Kali., reside en la barrida de la estación del tren.

ENTREVISTA PERSONAL 9 (2018): a mujer colombiana de 50 años de Kali., reside en Perez Galdós.

ENTREVISTA PERSONAL 10 (2018): a mujer de 33 años de Colombia de Valle Cuenca.

ENTREVISTA PERSONAL 11 (2018): a mujer de 19 años de Bolvia de Santa Cruz de la Sierra, reside en Ricardo Ortega.

ENTREVISTA PERSONAL 12 (2018): a mujer de 61 años Colombia de Kali, reside en Jeroni Pou.

ENTREVISTA PERSONAL 13 (2018): a mujer de 51 años de Colombia de Kali, reside en Capitan Vila.

Bibliografía

AGRELA, B. (2002): "La política de inmigración en España: reflexiones sobre la emergencia del discurso de la diferencia cultural", Migraciones Internacionales, 2 ene./jun, pp. 93-121.

ALONSO IGLESIAS, J. L. (2003): "Los derechos humanos de tercera generación y los movimientos sociales", Rev. Humanismo y Trabajo social, 2, pp. 47-70

ARA BALEARS (2018): “Els barris més desfavorits continuen assumint la població en augment de Palma", 27 de abril. Recuperado de https://www. arabalears.cat/societat/poblacio-palma-societat_0_2004399675. html.

ARIAS BARRERO, L. A. y CARRERA, P. E. (2014): "Etnicidad y re-etnización en las organizaciones de grupos étnicos desplazados en Bogotá", Revista Trabajo Social, 16, pp. 47-63.

BANCO MUNDIAL (2011): "Datos sobre migración y remesas 2011", www. worldbank.org/migration. Recuperado de https://siteresources. worldbank.org/INTPROSPECTS/Resources/334934-1110315015165/ Factbook2011Spanish.pdf.

BAUMAN, Z. (2002): La cultura como praxis, Barcelona: Paidós.

BAUMAN, Z. (2017): Desconaguts a la porta de casa, Barcelona, Arcàdia.

BECK, U. y BECK-GEMSHEIM, E. (2008): "Expectativas de igualdad y sueños de migración", en Generación global, Barcelona, Paidós, pp. 21-39

BHABHA, H.K. (2013): Nuevas minorías, nuevos derechos. Notas sobre cosmopolitismos vernáculos, Buenos Aires, Siglo XXI.

BENHABIB, S. (2006): Reivindicaciones de la cultura. Igualdad y diversidad en la era global. Buenos Aires, Katz editores.

BOHÓRQUEZ, L. (2017): “La Soledad y Son Gotleu, los barrios de Palma con mayores índices de exclusión", Recuperado de https://cadenaser.com/ emisora/2017/05/23/radio_mallorca/1495539208_562530.html.

BOURDIEU, P. (2000): La dominación masculina, Barcelona, Anagrama.

BUSQUET, J. (2005): Els escenaris de la cultura, Barcelona, Tripodos.

CAPÓ, J. (2012): "Diario de Palma. Inmigrantes por barrios". Diario de Mallorca de 2 de marzo. https://www.diariodemallorca.es/palma/2012/03/02/pere-garau-son-gotleu-acogen-20-habitantes-extracomunitarios/748881.html. 
CARBONELL, F. (1994): L'educació i la formació dels fills dels immigrants Revista de Girona, 162, enero - febrero, pp. 91-93

CARBONELL, F. (1995): Inmigración diversidad cultural, desigualdad social y educación, Madrid, Ministerio de Educación y Ciencia.

CARBONELL, F. (2003): Sobre la imposibilidad de educar la confianza Suposiciones y propuestas para una educación intercultural. Revista CIDOB d'Afers Internacionals, 61-62, pp. 155-176.

CASTELLS, M. y SUBIRATS, M. (2007): Mujeres y hombres iun amor imposible?, Madrid, Alianza.

CASTEL, R. (2010): La discriminación negativa, Barcelona, Editorial Hacer.

CHALÁ, J. (2001): "Comentarios presentados en el Taller Afro sobre etnoeducación", Universidad Andina Simón Bolívar, Quito, 27 de marzo de. Centro Cultural Afro-ecuatoriano. (2001) "Propuesta etnoeducativa". Palenque, 20 (1), marzo, pp. 2-3.

CHOMSKY, N. (2003): America Latina de la colonización a la globalización, Madrid, Cátedra.

CLASTRES, P. (2002): "De l'etnocidi", en Frade, C. (ed.), Globalització i diversitat cultural, Barcelona, Edicions Universitat Oberta de Catalunya.

CLIFFORD, J. (1995): Dilemas de la cultura, Barcelona, Gedisa.

CORTÉS, R. (2012): "El retorno voluntario se paraliza pese a mantenerse la demanda". Baleares sin fronteras de 25 de mayo. Recuperado de https://www.baleares-sinfronteras.com/

CURSAT, J. e IBÁÑEZ, O. (2013): “La crisi, un canvi d'actituds envers la immigració a les Illes Baleras", en Mulet, B., Diversitat, génere i ètnia en el marc de la globalització i la immigració, Palma, Edicions Universitat de les Illes Balears, pp. 153-163.

DELGADO, M.; MARTUCELLI, D.; ACTIS, W.; PALACÍN, I. y SÁEZ, P. (2002): Exclusión social y diversidad cultural, Donostia, Tercera Prensa.

DÍAZ GORFINKIEL, M. y MARTÍNEZ-BUJÁN, R. (2018): “Mujeres migrantes y trabajos de cuidados: transformaciones del sector doméstico en España", Rev. Panorama Social, Primer semestre, pp. 105-118.

DOBLAS, M. (2018): "La inmigración extranjera a Baleares sube un 33\% y alcanza niveles previos a la crisis", En diario Ultima Hora de 26 de junio. Recuperado de https://www.ultimahora.es/noticias/local/2018/06/26/1009333/inmigracion-extranjera-baleares-sube-alcanza-niveles-previos-crisis.html.

EL PAÍS (2013): "Colombia", 20 de septiembre. Recuperado de http:// www.elpais.com.co/colombia/es-el-pais-con-mayor-numero-de-emigrantes-en-suramerica.html.

EFE/Palma (2011): "Tres detenidos por altercados raciales en Palma de Mallorca", $A B C 29$ de agosto. Recuperado de https://www. abc.es/20110829/espana/abci-tres-detenidos-altercados-raciales-201108291021.html.

ENZENSBERGER, H. M. (2001): La gran migración, Barcelona, Anagrama.

ESTEBAN, G. (2017): "Absuelto el acusado de yihadismo de Son Gotleu", 10 de octubre. Recuperado de https://www.ultimahora.es/noticias/ local/2017/10/11/298787/absuelto-acusado-yihadismo-son-gotleu-porque-actuo-creyendo-colaboraba-cni.html.

EUROPA EXPRESS (2019): "Baleares lidera el récord de aumento de población en España gracias a los extranjeros", Recuperado de https:// www.ultimahora.es/noticias/local/2019/06/25/1090105/baleares-lidera-record-aumento-poblacion-espana-gracias-extranjeros.html.

EXPANSIÓN (2018): "Ecuador, emigrantes totales", https://www.datosmacro.com/demografia/migracion/emigracion/ecuador.

FRANZÉ, A. (2008): "Discurso experto, educación intercultural y patrimonialización de la cultura de origen", en María Isabel Jociles y Adela Franzé (eds.), ¿Es la escuela el problema? Perspectivas socioantropológicas de etnografía y educación, Madrid, Ed. Trotta.

FUNDACIÓN FOESSA (2018): Análisi y perspectivas. Exclusión Estructural e Integración Social. Madrid: Publicaciones Cáritas Española. FUNES, J. (1999): "Migración y adolescencia", en E. Aja, F. Carbonell, Colectivo loé, J. Funes y I. Vila, La inmigraciónextranjera en España. Los retos educativos, Barcelona, Fundación la Caixa, pp. 119-144.

GARRETA, J. (2009): Sociedad multicultural e integración de los imigrantes en Cataluña, Lleida, Edicions Universutat de Lleida.

GEERTZ, C. (1996): Los usos de la diversidad, Barcelona, Paidós.

GIDDENS, A. y SUTTON, P. W. (2014): Sociología, Madrid: Alianza Editorial.

GONZÁLEZ PÉREZ, J. M. y SOMOZA, J. (2004): “Territorio e inmigración en
España. Análisis de casos en Palma de Mallorca y León. Espacio, Sociedad, Territorio", Artículo 274, 22 de junio. Cybergeo. Recuperado de https://journals.openedition.org/cybergeo/ 25547.

GONZÁLEZ, M. (2017): “Una década de crisis económica deja en estado grave el Estado del Bienestar", https://www.elboletin.com/noticia/157341/nacional/una-decada-de-crisis-economica-deja-en-estado-grave-el-estado-del-bienestar.html.

GRIMSON, A. (2011): Los límites de la cultura. Critica de las teorías de la identidad, Buenos Aires, Siglo XXI.

GUIJARRO, F. (2018): "La población balear crece a la mayor velocidad de España con 1,1\% durante el último año", Diario de Mallorca, de 25 de abril. Recuperado de https://www.diariodemallorca.es/mallorca/2018/04/25/poblacion-balear-crece-mayor-velocidad/1307407. html.

GUIJARRO, F. (2019): “Son Gotleu es el barrio más pobre y sa Teulera el más rico", recuperado de https://www.diariodemallorca.es/mallorca/2019/09/12/son-gotleu-aparece-barrios-pobres/1447908.html.

GROSSBERG, L. (2006): "Stuart Hall sobre raza y racismo: estudios culturales y la práctica del contextualismo", Tabula Rasa, 5, julio-desembre, pp. 45-65.

HALL, S. y DU GAY, P. (1996 y 2003): Cuestiones de identidad cultural, Buenos Aires, Amorrortu Editores.

HALL, S. (1996 y 2003): "Introducción: ¿Quién necesita “identidad?", en Hall, S. i Du Gay, P., Cuestiones de identidad cultural, Buenos Aires, Amorrorturtu.

HALL, S. (2019): El triángulo funesto. Raza, etnia y nación, Madrid, Traficantes de Sueños.

HANNOUN, H. (1987): Els ghettos de l'escola. Per una educación intercultural, Vic, Eumo.

HERRERA, G. y MARTÍNEZ, A. (2002): Género y migración en la región Sur. Informe de investigación,Quito, Ecuador, FLACSO.

IBESTAT (Institut d'Estadística de les Illes Balears) (2018): "Padró de població 1996-2017", Conselleria de Treball, Comerç i Indústria. https: ibestat.caib.es.

INE (2020): "Cifras oficiales de población resultantes de la revisión del Padrón municipal a 1 de enero 1996-2019". Recuperado de https://www. ine.es/jaxiT3/Tabla.htm?t=2860.

INE (2012): Padrón a 1 de enero de 2012, Madrid, Instituto Nacional de Estadística.

INE (2016):“Cifras de Población a 1 de enero de 2016; Estadística de Migraciones 2015; Adquisiciones de Nacionalidad Española de Residentes 2015. Nota de prensa", recuperado de http://www.ine.es/prensa/ np980.pdf.

INE (2018): "Padrón, desde 2017 hasta el 13 de febrero de 2018", recuperado de https://padron.com.es/colombianos-en-illes-balears/.

INE (2018): Padrón a 1 de enero de 2016, Madrid, Instituto Nacional de Estadística.

IGLESIAS, J. et al. (2015): La población de origen ecuatoriano en España. Características, necesidades y expectativas en tiempo de crisis, Madrid, Embajada del Ecuador en Madrid-Universidad de Comillas.

JULIANO, D. (1993): Educación intercultural. Escuela y minorías étnicas, Madrid, Eudema.

JUSTICIA I PAU (1992): Immigració, racism i xenophobia a Mallorca, Palma de Mallorca, El Tall.

KYMLICKA, W. (1996): Ciudadanía multicultural, Barcelona, Paidós.

LABAT, C. y VERMES, G. (1994): Cultures ouvertes, sociétés interculturelles, Paris, L'Harmattan.

LOVELACE, M. (1995): Educación multicultural. Lengua y cultura en la escuela plural, Madrid, Escuela Española.

MACIONIS, J.J. y PLUMMER, K. (2007): Sociología, Madrid, Pearson.

MARINA, L. (2018): "Los clanes de narcos de Son Banya se trasladan a Son Gotleu, Marratxí y Llucmajor", Diario de Mallorca, 18 de febrero, p. 29.

MALAGÓN, V. (2016): "Operación en Son Gotleu contra el yihadismo". UItima Hora, 26 de abril. Recuperado de https://www.ultimahora.es/ noticias/local/2016/04/26/189478/supuesto-yihadista-dio-informacion-guardia-civil-sobre-narcos-son-gotleu.html.

MATTELART, A. (2005): Diversidad cultural y mundialización, Barcelona, Paidós. 
MAYORAL, D. y MATEO, D. (2012): "El llarg camí cap a la interculturalitat", en Rotger, J. Ma, Sociologia de l'educació, Barcelona, Roure, pp. 221-245.

MELIÀ, J. (1997): La llengua dels joves, Palma (Mallorca), Servei de Publicacions de la Universitat de les Illes Balers.

MELIÀ, J. (2004): "Immigració i normalització lingüística a les Illes Balears", Revista Lluc, 840, agosto, pp. 15-19.

MIRALLES, J.; GONZÁLEZ, J. M; VIDAÑA, L. y FERRAGUT, G. (2009): Tercer boom i migracions contemporànies a les Illes Balears de 1995 a 2008, Palma de Mallorca, Fundació càtedra Iberoamericana- Universitat de les Illes Baleras.

MERINO, R. y RABALDA, I. (2012): “Desigualtats socials i desigualtats educatives", en Rotger, J. Ma, Sociologia de l'educació, Barcelona, Roure, pp. 163-192.

MISHRA, R. (1994): El estado de bienestar en la sociedad capitalista. Políticas de desmantelamiento y conservación en Europa, America del Norte y Australia, Madrid, Ministerio de Asuntos Sociales.

NACIONES UNIDAS (1948): Declaración Universal de las Naciones Unidas, Paris, ONU.

NAÏR, S. (2005): "La modernidad en contra del «choque de civilizaciones»", en S. George, S. Naiir, I. Ramonet, T. Todorov, Frente a la razón del más fuerte, Barcelona, Círculo de Lectores.

NYBERG, N. y VAMMEN, I. M. (2016): “¿A quién le importa? Las familias transnacionales en los debates sobre la migración y el desarrollo", Investigaciones Feministas, 7 (1), pp. 191-220

ORTIZ, R. (2002): Otro territorio. Ensayos sobre el mundo contemporáneo, Universidad de Quiles, Buenos Aires.

OLLÉS, M. (2018): "Operación Lagos", Diario de Mallorca, 15 de febrero. Recuperado de https://www.diariodemallorca.es/sucesos/2018/02/15/.

ORGANIZACIÓN INTERNACIONAL PARA LAS MIGRACIONES-OIM (2013): Perfil Migratorio de Colombia 2012, Bogotá, OIM. Recuperado de https://www.iom.int/files/live/sites/iom/files/pbn/docs/Perfil-Migratorio-de-Colombia-2012.pdf.

ORGANIZACIÓN PARA LA COOPERACIÓN Y EL DESARROLLO ECONÓMICOS (OCDE) (2009): Perspectivas Económicas de América Latina 2010, Colombia. Recuperado de http://www.oecd.org/countries/colombia/45660669.pdf, pp. 245-248.

PARELLA, S. (2003): "La inserción laboral de la mujer inmigrante en los servicios de proximidad de Cataluña", Revista Internacional de Sociología (RIS), 36, septiembre-diciembre, pp. 85-113.

PARCERISA, LL. y VERGER, A. (2016): "Contra la imposició, defensem l'educació", Anuari de l'Educació de les Illes Balears", 2016, pp. 354-373

PUIGVERT, L. (2013): "La inclusió de les altres dones", en Mulet, B., Diversitat, génere i ètnia en el marc de la globalització i la immigració, Palma de Mallorca, Edicions Universitat de les Illes Balears, pp. 57-69.

RIBAS, N. (2004): Una invitación a la sociología de las migraciones, BarceIona, Edicions Bellaterra.

RUIZ, M. (2002): "Ni sueño ni pesadilla: diversidad y paradojas en el proceso migratorio", Iconos, 14, pp. 88-97.

SALVÀ, P. (1985): "Turisme i canvi a l'espai de les Illes Balears", Treballs de la Societat Catalana de Geografia, 2, abril, pp. 17-32.

SANTOS GUERRA, M. A. (1999): "Crítica de la eficacia y eficacia de la crítica", en Angulo, F. et al., Escuela pública y sociedad neoliberal, Madrid, Miño y Dávila, pp. 83-111.

SARTORI, G. (2001): La sociedad multiétnica. Pluralismo, multiculturalismo y extranjeros, Madrid, Taurus.

SASSEN, S. (2003): Cartografías de la globalización, Género y ciudadanía en los circuitos transfronterizos, Madrid, Traficantes de sueños.

SASSEN, S. (2004): "Formación de los condicionantes económicos para las migraciones Internacionales", Debate, 63, pp. 63-88.

SASSEN, S. (2007): Una sociología de la globalización, Madrid, Katz.

SERRA, C. (2006): Diversitat, racisme i viléncia, Vic, Eumo.

S.O.S. Racismo (2018): Informe anual sobre el racismo en el estado español, Federación S.O.S. https://sosracismo.eu/wp-content/uploads/2018/11/Informe-prensa.pdf.

TAPIA, M. (2014): "Bolivia, historia de migraciones: pasado y presente", en Solé, C. Parella S. y Petroff A. (cords.), Las migraciones bolivianas en la encrucijada interdisciplinar: evolución, cambios y tendencias, BarceIona, Servei de Publicacions de la UAB, pp. 9-29.
TARABINI, A. (2012): "Sociologia del currículum i de la praxi educativa", en Rotger, J.Ma (2012), Sociologia de l'Educació, Barcelona, El Roure, pp. 289-312.

TORT, A. (2019): "Tendéncies mundials, contradiccions insuperables", Perspectiva Escolar, 404, marzo-abril, pp. 71-73.

UNESCO (2001): Declaración Universal de la UNESCO sobre la Diversidad Cultural, recuperado de http://portal.unesco.org/es/ev.php-URL_ ID $=13179 \&$ URL_DO=DO_TOPIC\&URL_SECTION=201.html.

U.S. Census Bureau (2011): The Hispanic Population: 2010. https://www. census.gov/library/publications/2011/dec/c2010br-04.html.

VALENCIA, H. (1998): Los Derechos Humanos, Madrid, Acento.

VALLESPIR, J. (2006): "Multiculturalidad e interculturalidad. El caso de Illes Balears", en N. Llevot, La educación intercultural: Discursos y prácticas, Lleida, Edicions Universitat de Lleida, pp. 53-80.

VILLARRUEL, P. (2012): "Aminta Buenaño rinde cuentas tras un año al frente de la Embajada en España", El Universo, https://www.eluniverso.com/2012/12/20/1/1360/aminta-buenano-rinde-cuentas-tras-unano-frente-embajada-espana.html.

VAN DIJK, T. A. (2003): Dominación étnica y racismo discursivo en España y America Latina, Barcelona, Gedisa.

V.S. y S.C. (2018): "El supremo confirma que el decreto del Govern sobre la tarjeta sanitaria es nulo", Ultima Hora, 25 de abril, p. 16.

ZANFRINI, L. (2007): La convivencia interétnica, Madrid, Alianza. 